\title{
Assessment of fastness properties of knitted cotton fabric dyed with natural dyes: a sustainable approach of textile coloration
}

\begin{abstract}
Now-a-days, the importance of natural sources is eminent because the increased awareness created due to most of the adverse effects of synthetic products. In recent years, it has been significantly important to use non-toxic \& eco-friendly natural dyes to dye textile materials. Though a lot of research work was done on the application of natural dyes on textile materials, natural dyes was not been proved satisfactory. There is a main reason behind this which is the absence of a broad systematic study of the performance of these natural dyes. Extraction of natural dyes for the coloration of textile substrate is one of the most important research areas for the researchers. In this study, we tried to extract the natural dyes from Arjuna bark, myrobalan fruits, Bohera fruits and amla fruits. After extraction, cotton knitted fabric sample was dyed with extracted dyes by using mordant and without mordant. And then their colorfastness properties were evaluated.
\end{abstract}

Keywords: amla, arjuna, bohera, cotton fabrics, colorfastness, haritoky
Volume 5 Issue 3 - 2019

\author{
Mafzal Ahmed,' Tarikul Islam, ${ }^{2}$ Md. Rezaul \\ Karim,' Shahidul Kaiser,' Pallab Barua' \\ 'Department of Textile Engineering, Port City International \\ University, Bangladesh \\ ${ }^{2}$ Department of Textile Engineering, Jashore University of \\ Science and Technology, Bangladesh
}

\begin{abstract}
Correspondence: Tarikul Islam, Lecturer, Department of Textile Engineering, Jashore University of Science and Technology, Jashore-7408, Bangladesh, Tel +880 I722202322, Email matarikul.islam2014@gmail.com
\end{abstract}

Received: June 17, 2019 | Published: June 25, 2019

\section{Introduction}

Textile materials (natural and synthetic) used to be colored for value addition, for improving outlook and to attract the customers. ${ }^{1}$ Anciently, this purpose of coloring textile was initiated using colors from natural source, until synthetic dyes were invented and commercialized. For ready availability of pure synthetic dyes of different classes and its low cost advantages, most of textile dyers/ manufacturers shifted towards the use of synthetic colorant., ${ }^{2,3}$ Almost all the synthetic colorants being synthesized from petrochemical sources through hazardous chemical processes pose threat towards its eco-friendliness. ${ }^{4}$ There are two main ways to limit the environmental impact of textile processing. One is to construct sufficiently large and highly effective effluent treatment plants, and the other way is to make sure that the dyes and chemicals that are environment friendly. ${ }^{5}$ The rich biodiversity of our country has provided us plenty of raw materials, yet sustainable linkage must be developed between cultivation, collection and their use. Natural dyes can produce special aesthetic qualities, which, combined with the ethical significance of a product that is environmental friendly, gives value addition to textile production as craftwork and as an industry. ${ }^{6}$ Nature provides different coloring matters of vegetable, animal and mineral origin; used for dyeing since ancient times. The major advantage of natural dyes is that they are biodegradable, non-toxic, hygienic and colors soothing to human eyes. ${ }^{7}$ From different research work it was found that Arjun has a good scope for application on cotton fabrics with its eco-friendly nature, ${ }^{8,9}$ Haritaky contains considerable color strength for the application on cotton fabric as well as these dyes give very good anti-microbial characters on the cotton fabric and these are appreciably compatible with cotton fabric..$^{10,11}$

The present paper envisages the application of four natural dye sources:

(i) Terminalia Arjuna (ii) Terminalia chebula

\section{(iii) Terminalia bellirica}

(iv) Pyllanthus embelica.

They were selected for dyeing through extraction of dyes from their barks and fruits. Dyes were extracted from Arjuna barks, Haritaky fruits, Bohera fruits, Amloki fruits and cotton knit fabric was dyed with the help of mordant i.e. ferrous sulphate, potash alum and also without using any mordant. After dyeing, all the samples were tested by different testing instruments. The dyeing process was very unique and many outputs can be found from this project. And it can be used for further study and research work.

\section{Materials and methods}

\section{Materials}

Following materials are required for this research-

a. Fabric

b. Dye-stuffs

c. Mordant

\section{Selection of fabric}

$100 \%$ single jersey cotton knitted was collected from Super Knitting \& Dyeing Mills Ltd., Chittagong, Bangladesh. Fabric GSM was 140 .

\section{Dye-stuffs}

Arjuna dye: Terminalia Arjuna generally called as Arjuna is one which contains large amount of bio-actives in its bark. Arjuna tree is found in Bangladesh, Uttar Pradesh, Madhya Pradesh, West Bengal and central India. The bark of Arjuna contains large amount 
of flavanoids \& tannis. Extract of colorant from its bark powder has potential to act as natural dye having medicinal properties for textile substrate. Most natural dyes need a mordant to bond with fiber (metallic salt like alum) but Arjuna can dye fibers without mordant.

Haritaky dye: Terminalia chebula commonly known as Haritaky is found in India, Bangladesh, Nepal, Sri Lanka. A number of glycosides have been isolated from Haritaky. Other constituents including chebulin, chebulic acid tannic acid terflavin B a type of tannin is found in the ripe fruits. Extract of colorant from its fruits powder has potential to act as natural dye having medicinal properties for textile substrate. Most natural dyes need a mordant to bond with fiber (metallic salt like alum) but Haritaky can dye fibers without mordant.

Bahera dye: Terminalia bellirica known as bahera is found in India, Bangladesh. It contains fatty acid methyl ester. It is used for not only dyeing of textile materials but also have potential to add additional properties like anti-microbial properties.

Amloki dye: Pyllanthus emblica known as Amloki is found in India, Bangladesh. It contains high amounts of ascorbic acid, polyphenols, flavonoids, ellagic acid and gallic acid. It is used for not only dyeing of textile materials but also have potential to add additional properties like anti-microbial properties. It is also used as mordant for dye fixing (Figure 1). (i)

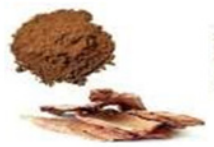

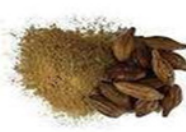

(ii)

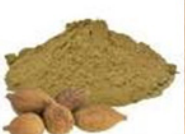

(iii)

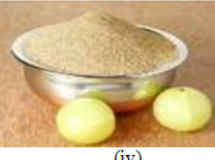

Figure I Different types of natural dye; (i) Arjuna Dyes (ii) Horitaky Dyes (iii) Bohera Dyes (iv) Amloki Dyes.

\section{Mordant}

There are evidences of dyeing textile materials with natural dyes since historic ages. But some key problems are yet to be solved for their wider uses. One of the difficultly is, these dyes are mostly nonsubstantive and need to be applied on textile materials with the help of mordants. Generally, metal salts of aluminum, iron, copper, chromium or tin are used for mordanting the fabric to help natural dye getting attached. Potash aluminum sulphate, ferrous sulphate or green vitriol, stannous chloride are well established mordant for the purpose.

In this project work ferrous sulphate and potash alum are used as mordant (Figure 2).

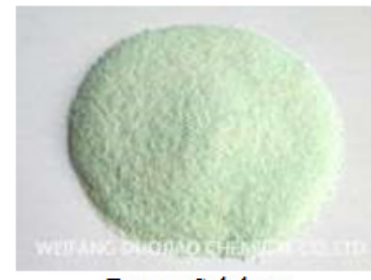

Ferrous Sulphate

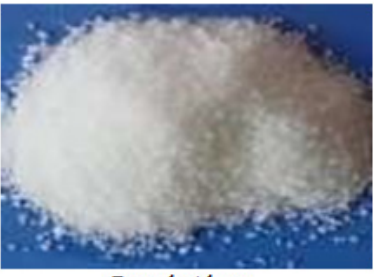

Potash Alum
Figure 2 Mordant used in work.

\section{Machinery}

a) Light Fastness Tester (Xenon Arc Light Fastness Tester) b) Washing Fastness Tester (Wascator)

c) Rubbing Fastness Tester (Crock Master)

\section{Methods}

Extraction of natural dyes: In our project work we used aqueous extraction method for dyes extraction where 100 gms of fine powder of dyes in 1 litre water was heated at boiling temperature for $2 \mathrm{hrs}$. And then the solution is filtered to get pure dye solution (Figure 3).

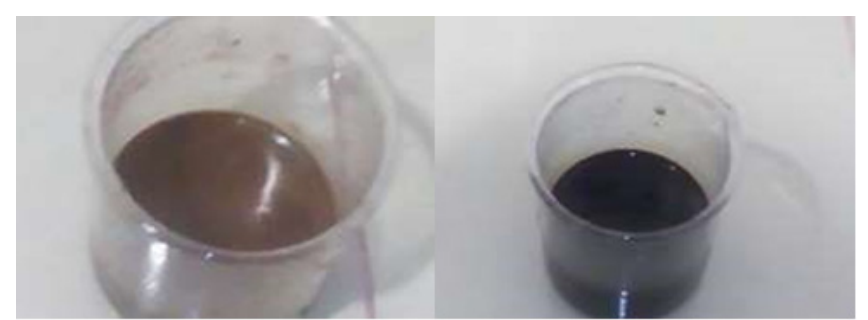

(i) (ii)

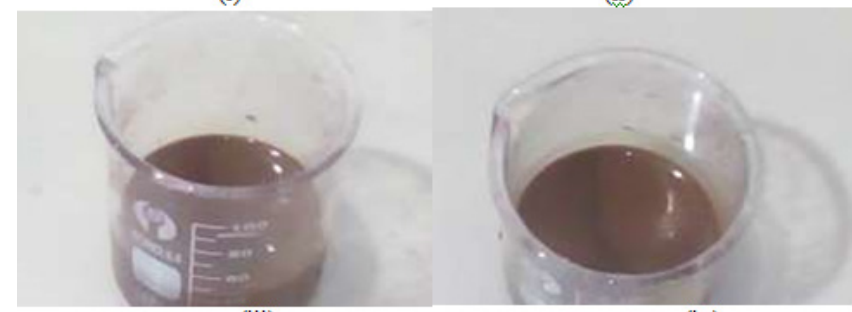

(iii)

(iv)

Figure 3 Extraction of natural dyes; (i) Arjun (ii) Horitaky (iii) Bohera (iv) Amloki.

\section{Mordanting}

Sixteen cotton fabric samples were taken for mordanting. Eight samples are for mordanting with $\mathrm{FeSO}_{4}$ and the others for mordanting with potash alum. $10 \mathrm{gm} / 1 \mathrm{FeSO}_{4} \&$ potash alum were taken in dye pot separately and it was heated with the scoured \& bleached cotton samples for $1 \mathrm{hr}$ at a temperature of $100^{\circ} \mathrm{C}$. After $1 \mathrm{hr}$ the fabrics were let for conditioning for $24 \mathrm{hrs}$. After washing these samples are dried (Figure 4).

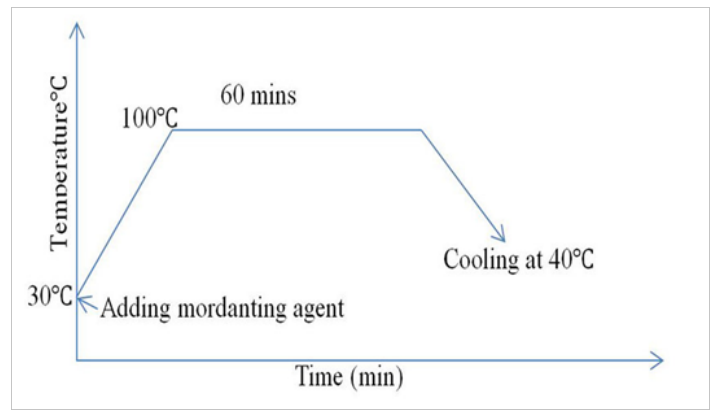

Figure 4 Fabric mordanting process curve.

\section{Recipe:}

i. Sample weight- $10 \mathrm{gm}$

ii. Mordant-10gm/1

iii. Time-60min 
iv. $\mathrm{Temp}-100^{\circ} \mathrm{C}$

v. M: L $-1: 30$

\section{Dyeing}

Dyeing the cotton fabric without mordant: Dyeing was carried out by exhaust method in sample dyeing machine $10 \mathrm{gm} / 1$ Arjuna dyes, Haritaky dyes, Bohera dyes, Amloki dyes were used for dyeing (Table 1) (Figure 5).

Table I Dyeing the cotton fabric without mordant

\begin{tabular}{ll}
\hline Dyeing recipe & After treatment recipe \\
\hline Sample weight $-10 \mathrm{gm}$ & Sample weight $-10 \mathrm{gm}$ \\
Leveling agent $-1.5 \mathrm{~g} / \mathrm{l}$ & Soaping agent $-1.5 \mathrm{~g} / \mathrm{l}$ \\
Dyes $-10 \mathrm{gm} / \mathrm{l}$ & Temp $-60^{\circ} \mathrm{C}$ \\
Time $-60 \mathrm{~min}$ & Time $-10 \mathrm{~min}$ \\
Temp $-80^{\circ} \mathrm{C}$ & \\
Soaping agent $-0.5 \mathrm{~g} / \mathrm{I}$ & \\
M:L $-1: 30$ & \\
\hline
\end{tabular}

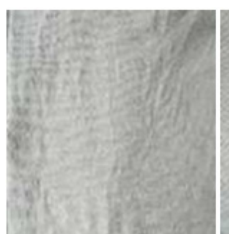

(i)

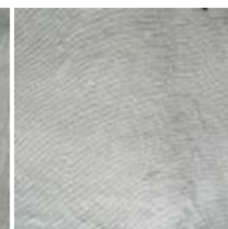

(ii)

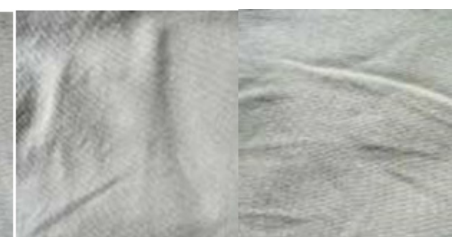

(iii)
Figure 5 Dyed fabric without mordant; (i) Amloki (ii) Bohera (iii) Arjun (iv) Horitaky.

\section{Procedures}

a. The liquor ratio is $1: 30$ at $80^{\circ} \mathrm{C}$ for 60 minutes in presence of $1.5 \mathrm{gm} / 1$ leveling agent.

b. Then the dye bath was cooled at $40^{\circ} \mathrm{C}$. Sample was washed at room temp. And samples was squeezed and dried in oven dryer machine.

c. Then sample was washed with $1.5 \mathrm{gm} / 1$ soaping agent where material and liquor ratio was $1: 30$ at $60^{\circ} \mathrm{C}$ for 10 minutes.

\section{Dyeing the cotton fabric mordanted with $\mathrm{FeSO}_{4}$}

Dyeing was carried out by exhaust method in sample dyeing machine 10gm/1 Arjuna dyes, Haritaky dyes, Bohera dyes, Amloki dyes were used for $10 \mathrm{gm}$ mordanted sample fabric (Table 2) (Figure $6)$.

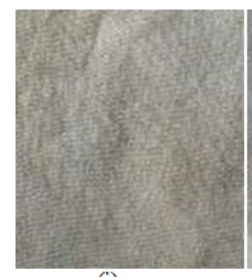

(i)

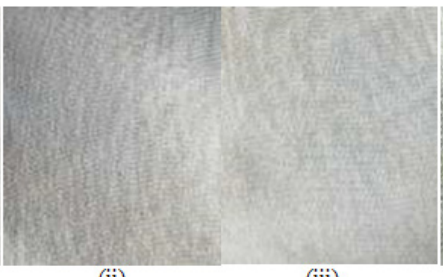

(ii)

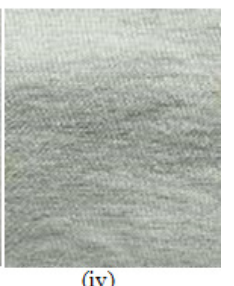

(iv)
Figure 6 Dyed fabric mordanted with FeSO4; (i) Amloki (ii) Bohera (iii) Arjun (iv) Horitaky.
Table 2 Dyeing the cotton fabric mordanted with $\mathrm{FeSO}_{4}$

\begin{tabular}{ll}
\hline Dyeing recipe & After treatment recipe \\
\hline Sample weight $-10 \mathrm{gm}$ & Sample weight $-10 \mathrm{gm}$ \\
Leveling agent $-1.5 \mathrm{~g} / \mathrm{l}$ & Soaping agent $-1.5 \mathrm{~g} / \mathrm{l}$ \\
Dyes $-10 \mathrm{gm} / \mathrm{l}$ & Temp $-60^{\circ} \mathrm{C}$ \\
Time $-60 \mathrm{~min}$ & Time $-10 \mathrm{~min}$ \\
Temp $-80^{\circ} \mathrm{C}$ & \\
Soaping agent $-0.5 \mathrm{~g} / \mathrm{l}$ & \\
$\mathrm{M}: \mathrm{L}-\mathrm{I:} 30$ &
\end{tabular}

\section{Procedures}

a. The liquor ratio is $1: 30$ at $80^{\circ} \mathrm{C}$ for 60 minutes in presence of $1.5 \mathrm{mg} / 1$ leveling agent.

b. Then the dye bath was cooled at $40^{\circ} \mathrm{C}$. Sample was washed at room temp. And samples was squeezed and dried in oven dryer machine.

c. Then sample was washed with $1.5 \mathrm{gm} / 1$ soaping agent where material and liquor ratio was $1: 30$ at $60^{\circ} \mathrm{C}$ for 10 minutes.

\section{Dyeing the cotton fabric mordanted with potash alum}

Dyeing was carried out by exhaust method in sample dyeing machine 10gm/1 Arjuna dyes, Haritaky dyes, Bohera dyes, Amloki dyes were used for $10 \mathrm{gm}$ mordanted sample fabric (Table 3) (Figure $7)$.

Table 3 Dyeing the cotton fabric mordanted with potash alum

\begin{tabular}{ll}
\hline Dyeing recipe & After treatment recipe \\
\hline Sample weight $-10 \mathrm{gm}$ & Sample weight $-10 \mathrm{gm}$ \\
Leveling agent $-1.5 \mathrm{~g} / \mathrm{l}$ & Soaping agent $-1.5 \mathrm{~g} / \mathrm{I}$ \\
Dyes $-10 \mathrm{gm} / \mathrm{I}$ & Temp $-60^{\circ} \mathrm{C}$ \\
Time $-60 \mathrm{~min}$ & Time $-10 \mathrm{~min}$ \\
Temp $-80^{\circ} \mathrm{C}$ & \\
Soaping agent $-0.5 \mathrm{~g} / \mathrm{I}$ & \\
M: L - I: 30 & \\
\hline
\end{tabular}

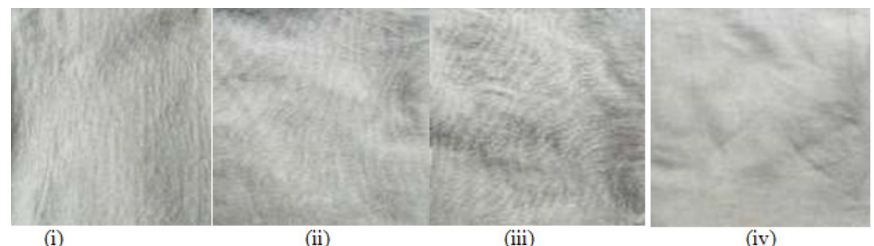

Figure 7 Dyed fabric mordanted with potash alum; (i) Amloki (ii) Bohera (iii) Arjun (iv) Horitaky.

\section{Procedures}

a) The liquor ratio is $1: 30$ at $80^{\circ} \mathrm{C}$ for 60 minutes in presence of $1.5 \mathrm{gm} / 1$ leveling agent.

b) Then the dye bath was cooled at $40^{\circ} \mathrm{C}$. Sample was washed at room temp. And samples was squeezed and dried in oven dryer machine.

c) Then sample was washed with $1.5 \mathrm{gm} / 1$ soaping agent where material and liquor ratio was $1: 30$ at $60^{\circ} \mathrm{C}$ for 10 minutes 


\section{Testing}

i. Color Fastness to Rubbing-ISO 105 X 12

ii. Color Fastness to Light- ISO 105 E03

iii. Color Fastness to Wash- ISO 105 C06

iv. CMC Test

\section{Results \& discussion}

Color fastness to rubbing: From Table 4, it is noticed that all dyes show better result without mordant $\&$ with potash alum and it's about 4. $\mathrm{FeSO}_{4}$ doesn't show good result, hence it is not compatible with these dyes as a mordant.

Table 4 Rubbing fastness properties of dyed fabric

\begin{tabular}{llll}
\hline Dyes source & Mordanting agent & $\begin{array}{l}\text { Dry } \\
\text { rubbibg }\end{array}$ & $\begin{array}{l}\text { Wet } \\
\text { rubbing }\end{array}$ \\
\hline Amloki & CONTROL & 4 & $3-4$ \\
& Ferrous Sulphate & $3-4$ & $2-3$ \\
& Potash Alum & 4 & $3-4$ \\
Bohera & CONTROL & 4 & $3-4$ \\
& Ferrous Sulphate & 4 & $3-4$ \\
\multirow{2}{*}{ Arjun } & Potash Alum & 4 & $3-4$ \\
& CONTROL & $4-5$ & 4 \\
& Ferrous Sulphate & $3-4$ & 3 \\
& Potash Alum & 4 & $3-4$ \\
Horitaky & CONTROL & $4-5$ & $3-4$ \\
& Ferrous Sulphate & $3-4$ & 3 \\
& Potash Alum & $3-4$ & $3-4$ \\
\hline
\end{tabular}

Table 6 Wash fastness properties of dyed fabric
Color fastness to light: From Table 5, In case of color fastness to light all dyes are fair to moderate. Amloki, Bohera, Haritaky shows better result for both mordanted and without mordanted sample. But Arjuna dyes don't show good result.

Table 5 Light fastness properties of dyed fabric

\begin{tabular}{lll}
\hline Dyes source & Mordanting agent & Grading \\
\hline Amloki & CONTROL & $3-4$ \\
& Ferrous Sulphate & 4 \\
\multirow{3}{*}{ Bohera } & Potash Alum & $3-4$ \\
& CONTROL & $3-4$ \\
& Ferrous Sulphate & 4 \\
Arjun & Potash Alum & 4 \\
& CONTROL & $2-3$ \\
& Ferrous Sulphate & 4 \\
Horitaky & Potash Alum & $2-3$ \\
& CONTROL & $3-4$ \\
& Ferrous Sulphate & 4 \\
& Potash Alum & 4 \\
\hline
\end{tabular}

Color fastness to wash: From Table 6, it shows that wash fastness of these dyes for change in color isn't good. But color staining is excellent. So, it is recommended to use these dyes for dyeing of fabric which need less wash like wound bandage.

CMC test: From Table 7, it shows that the higher the difference, the more the shade changes. In reference to sample without mordant, the mordanted sample gives darker \& red shade for both Amloki and Arjun. Bohera and horitaky gives darker and red shade for $\mathrm{FeSO}_{4}$ whereas darker and green for potash alum.

\begin{tabular}{|c|c|c|c|c|c|c|c|c|}
\hline \multirow{2}{*}{$\begin{array}{l}\text { Dyes } \\
\text { source }\end{array}$} & \multirow{2}{*}{ Mordanting agent } & \multirow{2}{*}{$\begin{array}{l}\text { Change } \\
\text { in color }\end{array}$} & \multicolumn{6}{|c|}{ Color staining } \\
\hline & & & Diacetate & Cotton & Polyamide & Polyester & Polyacrylic & Wool \\
\hline \multirow[t]{3}{*}{ Amloki } & CONTROL & 2 & $4-5$ & 4 & $4-5$ & $4-5$ & $4-5$ & $4-5$ \\
\hline & Ferrous Sulphate & 2 & $4-5$ & 4 & $4-5$ & 4 & 4 & $4-5$ \\
\hline & Potash Alum & $\mathrm{I}-2$ & $4-5$ & 4 & $4-5$ & $4-5$ & $4-5$ & $4-5$ \\
\hline \multirow[t]{3}{*}{ Bohera } & CONTROL & 3 & $4-5$ & 4 & $4-5$ & 4 & $4-5$ & $4-5$ \\
\hline & Ferrous Sulphate & 2 & $4-5$ & 4 & $4-5$ & $4-5$ & $4-5$ & $4-5$ \\
\hline & Potash Alum & 2 & $4-5$ & 4 & $4-5$ & $4-5$ & $4-5$ & $4-5$ \\
\hline \multirow[t]{3}{*}{ Arjun } & CONTROL & $\mathrm{I}-2$ & $4-5$ & 4 & 4 & 4 & $4-5$ & $4-5$ \\
\hline & Ferrous Sulphate & $\mathrm{I}-2$ & $4-5$ & 4 & $4-5$ & $4-5$ & $4-5$ & $4-5$ \\
\hline & Potash Alum & $\mathrm{I}-2$ & $4-5$ & 4 & $4-5$ & $4-5$ & $4-5$ & $4-5$ \\
\hline \multirow[t]{3}{*}{ Horitaky } & CONTROL & 2 & $4-5$ & 4 & $4-5$ & 4 & 4 & $4-5$ \\
\hline & Ferrous Sulphate & 2 & $4-5$ & 4 & $4-5$ & $4-5$ & $4-5$ & $4-5$ \\
\hline & Potash Alum & 2 & $4-5$ & 4 & $4-5$ & $4-5$ & $4-5$ & $4-5$ \\
\hline
\end{tabular}


Table 7 CMC value of dyed fabric

\begin{tabular}{|c|c|c|c|c|c|c|c|c|c|}
\hline Standard & $\begin{array}{l}\text { Sample } \\
\text { Batches }\end{array}$ & $\begin{array}{l}\text { Illuminant/ } \\
\text { Observer }\end{array}$ & DL* & $\mathbf{D a}^{*}$ & $\mathbf{D b} *$ & DC* & $\mathrm{DH}^{*}$ & DE & Remarks \\
\hline \multirow{2}{*}{$\begin{array}{l}\text { Almoki (Without } \\
\text { mordant) }\end{array}$} & with Ferrous Sulphate & & -17.42 & 2.68 & 0.95 & 1.45 & -2.45 & 17.65 & Darker + Red \\
\hline & with Potash Alum & & -5.86 & 0.95 & 3.66 & 3.74 & -0.53 & 6.97 & Darker + Red \\
\hline \multirow{2}{*}{$\begin{array}{l}\text { Bohera (Without } \\
\text { mordant) }\end{array}$} & with Ferrous Sulphate & & -14.82 & 2.56 & 0.19 & 0.55 & -2.5 & 15.04 & Darker + Red \\
\hline & with Potash Alum & & -6.86 & -0.29 & 4.72 & 4.71 & 0.44 & 8.33 & Darker + Green \\
\hline \multirow{3}{*}{$\begin{array}{l}\text { Arjun (Without } \\
\text { mordant) }\end{array}$} & & D65/I0 Deg & & & & & & & \\
\hline & with Ferrous Sulphate & & -7.74 & 6.12 & 8.64 & 9.51 & -4.65 & 13.11 & Darker + Red \\
\hline & with Potash Alum & & -0.43 & 0.2 & 1.31 & 1.32 & -0.2 & 1.4 & Darker + Red \\
\hline \multirow{2}{*}{$\begin{array}{l}\text { Horitaky (Without } \\
\text { mordant) }\end{array}$} & with Ferrous Sulphate & & -13.3 & 3.11 & 3.16 & 3.66 & -2.5 & 14.02 & Darker + Red \\
\hline & with Potash Alum & & -7.53 & -0.46 & 5.19 & 5.15 & 0.79 & 9.15 & Darker + Green \\
\hline
\end{tabular}

From the overall testing data it has been concluded that without the aid of mordanting agents the applied natural dyes show better results in fastness properties. It may happen due to the presence of tannic acid in those dyes which is act as mordanting agent itself. But from CMC test it has been claimed that the shade variety is profound after using different mordanting agents.

\section{Conclusion}

In the present scenario, the growing concerns among the communities globally against the use of azo and benzidine synthetic dyes due to their carcinogenic, non-biodegradable nature and hazardous effects on environment and human health. With increasing in awareness for eco-friendly materials from sustainable resources, natural dyes attracted researchers in traditional and diversified applications to develop effective eco-friendly and cleaner process technologies. Natural dyeing is gradually making its way in the global market and the production of naturally dyed eco-friendly textiles itself is a boon to save the environment from hazardous synthetic dyes. Furthermore, the fast moving inexpensive synthetic dyes stand as a big question before natural dyers. But, the non-toxic, non-carcinogenic, biodegradable and eco-friendly characteristics of naturally derived colorants made its own way to reach the hearts of conscious consumers for healthy lifestyle, and can be achieved on a higher cost. Hence, the applications of bio-colorants to textile substrates will be helpful to entrepreneurs to take up this venture which have good potential and bright future in a number of applied sectors: leather, textiles and clothings, cosmetics, food, pharmaceutical, and paint industries etc.

In this research it is shown that studied dyes are compatible with cotton fabric but the wash fastness is so poor. With further research it may be possible to apply different metal salts to enhance the wash fastness properties. Moreover, this research is based on lab scale but for the use of industrial purpose the dye extraction process should be in efficient manner. We used here aqueous extraction methods which may be replaced by solvent extraction method for getting more dyes and liquid dyes may convert into solid form which will be very much helpful for industrial purpose.

\section{Author contributions}

M.A. and M.R.K. planned and supervised the work. Moreover, S.K. and M.R.K. have done the specimen fabrication, characterization, testing, data analysis, and presentation part with the help of T.I. All authors read and finally approved the manuscript

\section{Acknowledgments}

None.

\section{Conflicts of interest}

The authors declare that they have no competing interests.

\section{References}

1. Saravanan P, Chandramohan G, Mariajancyrani J, et al. Extraction and application of eco - friendly natural dye obtained from leaves of Acalypha indica Linn on cotton fabric. International research journal of environment science. 2013;2(12):1-5.

2. Anna H, Christian RV. The potential use of organically grown dye plants in the organic textile industry. Journal of Sustain Agriculture. 2003;23(2):1740.

3. Ferreira E, Hulme A, Macnab H, et al. The natural constituents of historical textile dyes. Chemical Society Reviews. 2004;33(6):329-336.

4. Yadav S, Rose N, Singh J, et al. Natural dye powder: an easy technique for eco-dyeing, Research Journal of Recent Sciences. 2013;2:308-311.

5. Kumaresan M, Palnisamy P, Kumar PE. Application of eco-friendly natural dye obtained from flower of Spathodea Campanulata on silk. European Journal of Scientific Research. 2011;52(3):306-312.

6. Shyam VS, Purohit MC. Dyeing of wool fabrics with extracted ecofriendly natural dyes from Rhus Parviflora (Tung) using chemical mordants: Comparison of fastness properties and colour strength with some mordants. Chemical Science Transactions. 2014;3(3):1124-1130.

7. Samanta AK, Agarwal P. Application of natural dyes on textiles. Indian Journal of Fibre and Textile Research. 2009;34:384-399. 
8. Saivaraj S, Chandramohan G, Saravanan P. Dyeing of cotton with ecofriendly natural dye extract from barks of Terminalia Arjuna L. International Journal of Academic Research and Development. 2018;3(3):303-307.

9. Rane S, Hate M, Hande P, et al. Dyeing of cotton with Tectonagrandis leaves and Terminalia Arjuna bark extracts. International journal of textile science. 2017;6(2):72-75.
10. Murugajothi K, Moses, Jeyakodi J. Characteristics improvement of property of Terminalia chebula (Myrobalan) on cotton fabric. Oriented journal of chemistry. 2008;24(3):903-910.

11. Rathindramoorthy R, Thilagavathi G. Optimization of process conditions of cotton fabric treatment with Terminaliachebula extract. Indian journal of fibre \& textile Research. 2013;38:293-303. 